\title{
Synthesis, crystal structures, spectroscopic characterization and in vitro antidiabetic studies of new Schiff base Copper(II) complexes
}

\author{
SUNDARAMURTHY SANTHA LAKSHMI ${ }^{\mathrm{a}}$, KANNAPPAN GEETHA ${ }^{\mathrm{b}, *}$, M GAYATHRI $^{\mathrm{c}}$ and \\ GANESH SHANMUGAM ${ }^{\mathrm{d}}$ \\ a Department of Chemistry, D K M College for Women, Vellore, Tamil Nadu, 632 001, India \\ ${ }^{b}$ Department of Chemistry, Muthurangam Govt. Arts College, Vellore, Tamil Nadu, 632 002, India \\ ${ }^{\mathrm{c}}$ Department of Biotechnology, School of Bio-Sciences and Technology, VIT University, Vellore, \\ Tamil Nadu, 632 014, India \\ ${ }^{\mathrm{d} B i o o r g a n i c}$ Chemistry Laboratory, CSIR-Central Leather Research Institute, Adyar, Chennai, \\ Tamil Nadu, 600 020, India \\ e-mail: santhalakshmi_s@yahoo.com; geethamgacchem@gmail.com; gayathrigopinath@vit.ac.in; \\ ganesh@clri.res.in
}

MS received 9 February 2016; revised 25 April 2016; accepted 29 April 2016

\begin{abstract}
Two new Schiff base copper(II) complexes, $\left[\mathrm{CuL}^{1}(\operatorname{tmen})\right]$ (1) and $\left[\mathrm{Cu}_{2} \mathrm{~L}_{2}^{2}\right.$ (tmen) $]$ (2) \{where, $\mathrm{H}_{2} \mathrm{~L}^{1}=\mathrm{N}$-(salicylidene)-L-valine, $\mathrm{H}_{2} \mathrm{~L}^{2}=\mathrm{N}$-(3,5-dichlorosalicylidene)-L-valine and tmen $=\mathrm{N}, \mathrm{N}, \mathrm{N}^{\prime}, \mathrm{N}^{\prime}$ tetramethylethylene-1,2-diamine have been synthesized and characterized by molar conductance, elemental analyses, VSM-RT, UV-Vis, FTIR, EPR, and CD spectra. Both the complexes were structurally characterized by single crystal XRD. The crystal structure of complex 1 displays a distorted square pyramidal geometry in which Schiff base is coordinated to the $\mathrm{Cu}$ (II) ion via ONO-donor in the axial mode, whereas, the chelating diamine displays axial and equatorial mode of binding via NN-donor atoms. The crystal structure of the complex 2 reveals a syn-anti mode of carboxylate bridged dinuclear complex, in which, the coordination geometry around $\mathrm{Cu}(1)$ is square pyramid and distorted square planar around $\mathrm{Cu}(2)$. The target complexes were screened for in vitro antidiabetic activity. Both the complexes showed good inhibitory activity for $\alpha$-amylase and $\alpha$-glucosidase.
\end{abstract}

Keywords. Schiff base; Copper(II) complexes; crystal structure; syn-anti mode; antidiabetic.

\section{Introduction}

Diabetes mellitus is an endocrine disorder, which causes $9 \%$ of deaths worldwide. A survey reported that diabetes mellitus is affecting $10 \%$ of the population every year in developing countries. ${ }^{1}$ WHO predicted that the morbidity and mortality rate is increasing rapidly due to diabetes. ${ }^{2}$ To prevent this death rate many medications are used, however they failed to alleviate the complications. Treating diabetes with metal complexes is a new therapeutic strategy. Coulson and Dandona reported that $\mathrm{ZnCl}_{2}$ stimulate lipogenesis in rat adipocytes, similar to the action of insulin. ${ }^{3}$ The transition metal complexes were described to exhibit insulin mimetic effect as well as $\alpha$-amylase and $\alpha$-glucosidase inhibition activity. ${ }^{4}$ Copper is one of the transition metal found in heart, lungs, liver and gall bladder. Copper is essential to maintain the normal structure and function

*For correspondence of cells, and required for survival and growth. It plays a significant role in electron transfer reactions ${ }^{5}$ and involved in an iron metabolism, immune system, normal metabolism of glucose and cholesterol. Decrease in copper level results in oxidative damage and other metabolic changes. ${ }^{6}$ Various studies have been conducted on copper complexes and proved their different pharmacological actions such as antiulcer, anticonvulsant, anticancer, antidiabetic and antimicrobial activity. ${ }^{7-10}$

Since interdisciplinary research is a milestone of coordination chemistry, many researchers focus on the areas like catalysis, photochemistry, molecular modelling and biological studies. ${ }^{11}$ Until now, amino acid Schiff base copper(II) complexes containing NN-donor heterocyclics like 1,10-phenanthroline, 2,2'-bipyridine have been reported, ${ }^{12,13}$ whereas, use $\mathrm{NN}$-donor aliphatic compounds was not yet reported. Similarly, most of the reported ternary $\mathrm{Cu}(\mathrm{II})$ complexes containing Schiff bases and heterocylic compounds were analysed for antimicrobial, antitumor and antioxidant activities. ${ }^{14,15}$ 
The complexes derived from Schiff bases, ${ }^{16,17}$ especially those of salicylidene amino acids, have potential biological properties. ${ }^{18}$ Vančo et al. ${ }^{19}$ reported in vivo antidiabetic activity of $\mathrm{Cu}$ (II) and $\mathrm{Zn}$ (II) complexes derived from $\mathrm{N}$-salicylidene- $\beta$-alanine. Herein, we report the synthesis of new Schiff base $\mathrm{Cu}$ (II) complexes $\mathbf{1}$ and $\mathbf{2}$ containing $\mathrm{NN}$-donor aliphatic chelating diamine, tmen (N,N,N $\mathrm{N}^{\prime} \mathrm{N}^{\prime}$-tetramethylethylene-1,2diamine) and study of the in vitro antidiabetic activity. According to the literature, electron withdrawing substituents present in the phenyl ring of the Schiff bases show very good antimicrobial and other biological properties. ${ }^{20,21}$ Hence, we have chosen chloro substituent in case of $\mathrm{H}_{2} \mathrm{~L}^{2}$.

\section{Experimental}

\subsection{Chemicals and physical measurements}

All the reagents and chemicals were procured from commercial sources and were used as received. L-valine was obtained from SD Fine chemicals, Mumbai. Salicylaldehyde and 3,5-dichlorosalicylaldehyde were purchased from Sigma Aldrich and tmen $\left(\mathrm{N}, \mathrm{N}, \mathrm{N}^{\prime}, \mathrm{N}^{\prime}-\right.$ tetramethylethylene-1,2-diamine) was purchased from Central Drug House (P) Ltd, Mumbai. Chemicals such as $\alpha$-amylase, $\alpha$-glucosidase, soluble starch, glucose and DMSO were purchased from Sisco Research Laboratories Pvt. Ltd., Mumbai. Dialysis membrane and 3,5-dinitro salicylic acid (DNSA) were purchased from Himedia Laboratories, Mumbai.

Elemental analyses $(\mathrm{C}, \mathrm{H}$ and $\mathrm{N})$ of the complexes were performed on Flash 2000 organic elemental analyzer. Magnetic moment of both the complexes was obtained using a VSM Lake Shore-7404 at room temperature and diamagnetic corrections were made using Pascal's constants. The molar conductance of the complexes were measured in DMF $\left(10^{-3} \mathrm{M}\right)$ solution using a direct reading conductivity meter at room temperature. The UV-Visible spectra of both the complexes $(0.05 \mathrm{mg} / \mathrm{mL})$ were recorded in ethanol, in the region of 200-800 nm using a Perkin-Elmer Lambda EZ201 UV-Vis spectrophotometer at room temperature. A rectangular quartz cell with path length of $1 \mathrm{~cm}$ was used. Circular dichroism spectra were measured using JASCO J-715 spectropolarimeter at room temperature. CD spectra of both the complexes $(0.25 \mathrm{mg} / \mathrm{mL})$ were recorded in ethanol, in the wavelength range of 200-800 $\mathrm{nm}$. A quartz cell with a path length of $1 \mathrm{~mm}$ was used. Each spectrum represents an average of three individual scans. FTIR spectra of the complexes were recorded in the region of $4000-400 \mathrm{~cm}^{-1}$ on IR Affinity-1S Shimadzu FTIR spectrophotometer using the conventional
$\mathrm{KBr}$ pellet methodology. The EPR spectra of the complexes were recorded in the polycrystalline state on Bruker EPR spectrometer (EMX-10/2.7) using DPPH as $\mathrm{g}$-marker at liquid nitrogen temperature.

\subsection{Synthesis}

Complex 1 was synthesized by adding an aqueous solution of L-valine ( $1 \mathrm{mmol}, 0.12 \mathrm{~g}$ ) and potassium hydroxide ( $2 \mathrm{mmol}, 0.12 \mathrm{~g}$ ) to an ethanolic solution (25 $\mathrm{mL}$ ) of salicylaldehyde ( $1 \mathrm{mmol}, 0.1 \mathrm{~mL})$ and the mixture was stirred at $333 \mathrm{~K}$ for $1 \mathrm{~h}$. Then, hydrated copper(II) acetate ( $1 \mathrm{mmol}, 0.201 \mathrm{~g}$ ) was added and the solution was stirred for an hour at $333 \mathrm{~K}$ followed by addition of tmen $(1 \mathrm{mmol}, 0.1 \mathrm{~mL})$ in drops and the solution was stirred for additional $2 \mathrm{~h}$ at the same temperature. The resultant green coloured turbid solution was filtered and kept at room temperature to evaporate the solvent. Similarly, complex $\mathbf{2}$ was prepared in the same way as complex $\mathbf{1}$ using 3,5-dichloro salicylaldehyde ( $1 \mathrm{mmol}, 0.195 \mathrm{~g})$ instead of salicylaldehyde.

The analytical data of the complexes are given below.

Complex 1: M.P.: $182^{\circ} \mathrm{C} ; \mu_{\text {eff }}=1.76$ B.M.; $\Lambda_{\mathrm{M}}=$ $3 \Omega^{-1} \mathrm{~cm}^{2} \mathrm{~mol}^{-1}$; Elemental analysis (\% Found/calculated) for $\mathrm{C}_{18} \mathrm{H}_{29} \mathrm{CuN}_{3} \mathrm{O}_{3} \mathrm{C}: 55.22 / 54.19 ; \mathrm{H}: 7.35 / 7.33$; N: $10.51 / 10.53$. Complex 2: M.P.: $204^{\circ} \mathrm{C} ; \mu_{\text {eff }}=1.58$ B.M.; $\Lambda_{\mathrm{M}}=3.5 \Omega^{-1} \mathrm{~cm}^{2} \mathrm{~mol}^{-1}$; Elemental analysis (\% Found /calculated) for $\mathrm{C}_{30} \mathrm{H}_{38} \mathrm{Cl}_{4} \mathrm{Cu}_{2} \mathrm{~N}_{4} \mathrm{O}_{6} \mathrm{C}$ : 43.98/43.97; H: 4.69/4.67; N: 6.85/6.84.

\section{$2.3 X$-ray crystal structure determination}

Single crystals suitable for X-ray diffraction study for the complex 1 were grown by slow evaporation of the DMF solution at room temperature, whereas for complex 2 , it was obtained by the slow evaporation of the solvent from the mother liquor at room temperature. Single crystal diffraction data of the complexes were collected on Bruker single crystal Kappa Apex II diffractometer equipped with graphite monochromatized Mo-K $\alpha$ radiation $(\lambda=0.71073 \AA)$. A green coloured crystal of the complex 1 having the size $0.2 \times$ $0.25 \times 0.25 \mathrm{~mm}$ (and for complex 2 of the size $0.3 \times$ $0.28 \times 0.25 \mathrm{~mm}$ ) was mounted on a glass fibre and was used for data collection.

The structure of the complexes was solved by direct methods, using SHELXS-97 and refined by full-matrix least-squares techniques against $\mathrm{F}^{2}$ with anisotropic thermal parameters for all non-hydrogen atoms using SHELXL-97. ${ }^{22}$ A summary of pertinent crystal data along with further details of structure determination and refinement is given in table S1, Supporting 
information. Mercury 3.7 version was used to present the ORTEP view of the crystal structures.

2.3a Crystal data: Complex 1: $\mathrm{C}_{18} \mathrm{H}_{29} \mathrm{CuN}_{3} \mathrm{O}_{3}$, F. Wt. $=398.98$, tetragonal, space group $\mathrm{P}_{3}, \mathrm{a}=10.627(5)$, $\mathrm{b}=10.627(5), \mathrm{c}=18.048(5) \AA$ and $\alpha=\beta=\gamma=90^{\circ}$, $\mathrm{V}=2038.2(15) \AA^{3}, \mathrm{Z}=4, \rho=1.300 \mathrm{~g} / \mathrm{cm}^{3}, \mathrm{~F}(000)=$ $844, \theta$ range $=1.92$ to $28.33^{\circ}$, Final R1 $=0.0397, w R 2$ $=0.0934$.

Complex 2: $\mathrm{C}_{30} \mathrm{H}_{38} \mathrm{Cl}_{4} \mathrm{Cu}_{2} \mathrm{~N}_{4} \mathrm{O}_{6}$, F. Wt. $=819.52$, Orthorhombic, space group $P 2{ }_{1} 2_{1} 2_{1}, \mathrm{a}=11.8583(2), \mathrm{b}$ $=14.6280(2), \mathrm{c}=20.1371(3) \AA$ and $\alpha=\beta=\gamma=90^{\circ}$, $\mathrm{V}=3493.05(9) \AA^{3}, \mathrm{Z}=4, \rho=1.558 \mathrm{~g} / \mathrm{cm}^{3}, \mathrm{~F}(000)=$ $1680.0, \theta$ range $=2.65$ to $29.24^{\circ}$, Final $\mathrm{R} 1=0.0410$, $\mathrm{wR}_{2}=0.1107$.

\subsection{In vitro antidiabetic activity}

Glucose diffusion inhibition assay and percentage inhibition of the enzymes $\alpha$-amylase and $\alpha$-glucosidase were carried out in DMSO by previously optimized procedure. ${ }^{23}$ Standard drug acarbose was used as positive control for calculating $\mathrm{IC}_{50}$ values.

All the values are represented as Mean \pm SEM of triplicates. Microsoft office excel was used to calculate SEM and $\mathrm{IC}_{50}$ were calculated by GraphPad Prism 5.0 version. Values are considered significant with $\mathrm{p} \leq 0.05$.

\section{Results and Discussion}

Both the complexes are stable and readily soluble in solvents such as $\mathrm{CHCl}_{3}$, DMSO and DMF at room temperature. To study the electrolytic nature of the complexes, molar conductivities were measured in DMF at $10^{-3}$ M. The lower molar conductivity values of 3 and 3.5 $\Omega^{-1} \mathrm{~cm}^{2} \mathrm{~mol}^{-1}$ for the complexes $\mathbf{1}$ and $\mathbf{2}$, respectively, substantiate the non-electrolytic nature. ${ }^{24}$

\subsection{X-ray crystallography}

A summary of pertinent selected bond lengths and bond angles for the complexes $\mathbf{1}$ and $\mathbf{2}$ are given in table S2, in Supporting information.

3.1a Structure description of complex 1: An ORTEP view of the complex $\mathbf{1}$ along with the atom numbering scheme is shown in figure 1.

In general, $\mathrm{Cu}(\mathrm{II})$ complexes exist with either square pyramidal (spy) or trigonal bipyramidal (tbp) geometry in case of pentadentate coordination. Some of the $\mathrm{Cu}$ (II) complexes have been found to possess intermediate

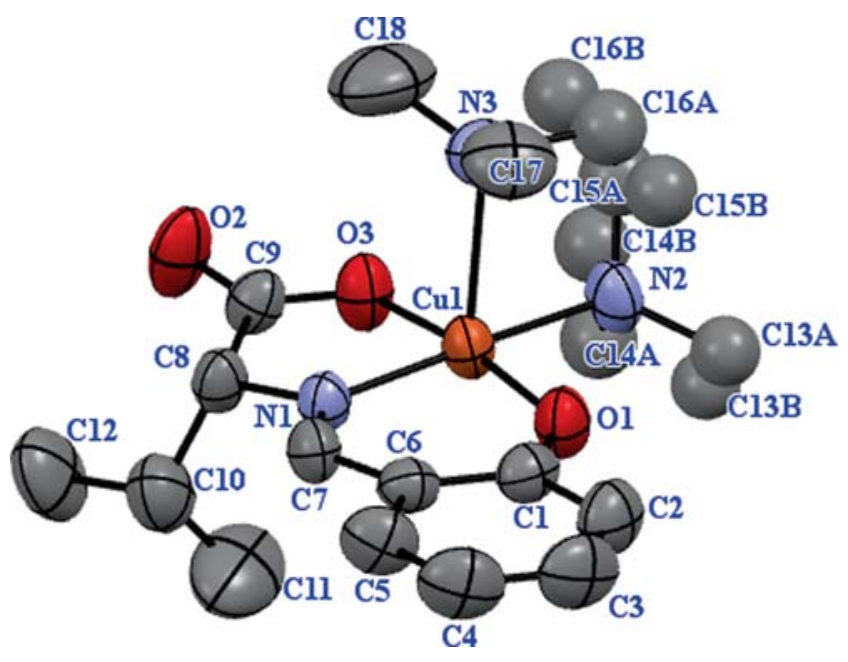

Figure 1. An ORTEP diagram of the complex 1 with the numbering scheme. (Hydrogen atoms are omitted for clarity).

geometry between spy and tbp. ${ }^{25}$ In case of five coordinated metal complexes, angular structural parameter (index of trigonality) $\tau\{\tau=(\beta-\alpha) / 60$, where $\alpha$ and $\beta$ are the two largest coordination angles $\}$, helps us for distinguishing the geometry between tbp and $\mathrm{spy}^{26} \mathrm{In}$ general, $\tau=0$ for an ideal spy and $\tau=1$ for ideal tbp geometry. Taking the angles $\mathrm{N}(2)-\mathrm{Cu}(1)-\mathrm{N}(1)$ as $\beta$ $\left\{173.32^{\circ}\right\}$ and $\mathrm{O}(1)-\mathrm{Cu}(1)-\mathrm{O}(3)$ as $\alpha\left\{171.85^{\circ}\right\}, \tau$ is calculated as 0.0245 . This indicates that the geometry of the complex $\mathbf{1}$ is close to the square pyramidal with a slight distortion.

In the square pyramidal geometry of complex $\mathbf{1}$, basal plane is occupied by imine nitrogen atom $\mathrm{N}(1)$, phenolate oxygen atom $\mathrm{O}(1)$, one of the oxygen atom $\mathrm{O}(3)$ of carboxylate group of Schiff base ligand and one of the nitrogen atom $\mathrm{N}(2)$ of tmen. The axial site is occupied by another nitrogen atom N(3) of tmen. The methylene carbon atoms of tmen namely $\mathrm{C}(15)$ and $\mathrm{C}(16)$ as well as $\mathrm{N}$-methyl carbon atoms $\mathrm{C}(13)$ and $\mathrm{C}(14)$ exhibit disorder. The $\mathrm{Cu}(1)-\mathrm{N}(1), \mathrm{Cu}(1)-$ $\mathrm{N}(2), \mathrm{Cu}(1)-\mathrm{O}(1), \mathrm{Cu}(1)-\mathrm{O}(3)$ distances are 1.941(3) $\AA, 2.065(3) \AA, 1.907(3) \AA$ and 1.9499(3) $\AA$, respectively. The basal bond angles $\mathrm{N}(1)-\mathrm{Cu}(1)-\mathrm{O}(1), \mathrm{N}(2)-$ $\mathrm{Cu}(1)-\mathrm{O}(1), \mathrm{N}(2)-\mathrm{Cu}(1)-\mathrm{O}(3)$ and $\mathrm{O}(3)-\mathrm{Cu}(1)-\mathrm{N}(1)$ are $92.80(12)^{\circ}, 91.29(12)^{\circ}, 91.9(13)^{\circ}$ and $83.33(11)^{\circ}$, respectively, and the $\mathrm{Cu}(1)-\mathrm{N}(3)$ apical bond length is 2.415(4) $\AA$ and this is longer than the equatorial bonds as expected. ${ }^{27}$ Further, the sum of the angles around $\mathrm{Cu}(1)$ is found to be $359.82^{\circ}$, which confirms that the central metal, $\mathrm{Cu}$ (II) ion lies in the plane.

3.1b Structure description of complex 2: An ORTEP view of the complex $\mathbf{2}$ along with the atom numbering scheme is shown in figure 2. 


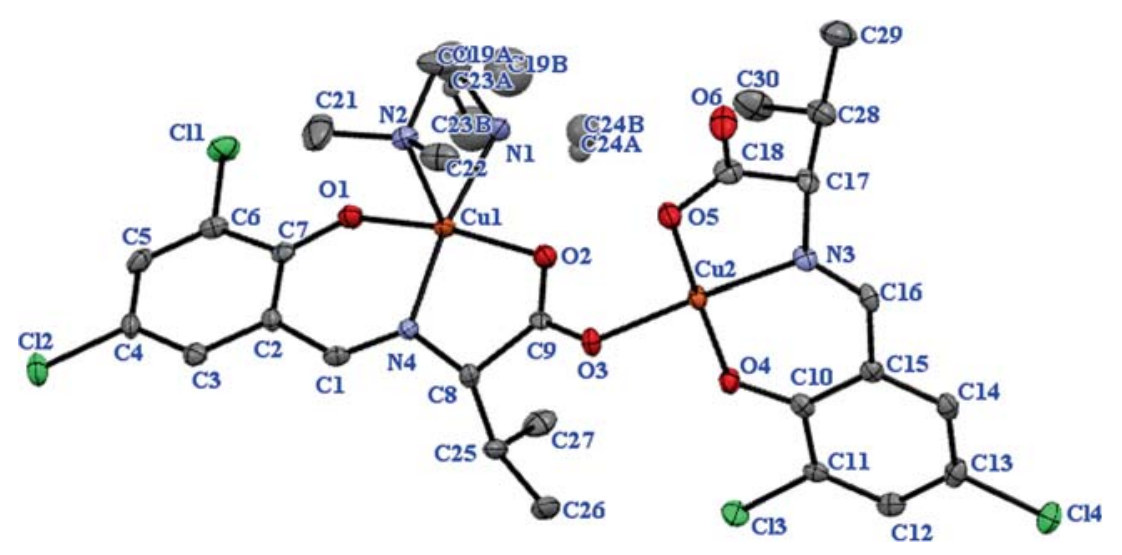

Figure 2. An ORTEP diagram of complex 2 with the numbering scheme. (Hydrogen atoms are omitted for clarity).

The coordination environment around $\mathrm{Cu}(1)$ is $\mathrm{N}_{3} \mathrm{O}_{2}$. The coordination of $\mathrm{Cu}(1)$ is constituted by the phenolate oxygen $\mathrm{O}(1)$, imine nitrogen $\mathrm{N}(4)$, oxygen atom $\mathrm{O}(2)$ of the carboxylate group of Schiff base ligand and the two nitrogen atoms $\mathrm{N}(1)$ and $\mathrm{N}(2)$ of tmen. By taking $\mathrm{N}(1)-\mathrm{Cu}(1)-\mathrm{N}(4)$ as $\beta\left\{171.6^{\circ}\right\}$ and $\mathrm{O}(1)-$ $\mathrm{Cu}(1)-\mathrm{O}(2)$ as $\alpha\left\{169.8^{\circ}\right\}$, the value of $\tau$ is calculated as 0.03 . This $\tau$ value is nearly same as that of complex $\mathbf{1}$. Hence the coordination geometry around $\mathrm{Cu}$ (1) can be described as very close to square pyramid. The basal plane of the square pyramid is coordinated by the imine nitrogen N(4) of the Schiff base ligand, phenolate oxygen atom $\mathrm{O}(1)$, oxygen atom $\mathrm{O}(2)$ of the carboxylate group and one of the nitrogen atom $\mathrm{N}(1)$ of the tmen, whereas the apical position is occupied by the nitrogen atom $\mathrm{N}(2)$ of tmen. The carboxylate group belonging to the Schiff base ligand around $\mathrm{Cu}(1)$ acts a tetradentate ligand, by bridging $\mathrm{Cu}(1)$ and $\mathrm{Cu}(2)$. The apical bond length $2.323 \AA$ of $\mathrm{Cu}(1)-\mathrm{N}(2)$ is longer than the basal distance $2.326 \AA$ of $\mathrm{Cu}(1)-\mathrm{N}(1){ }^{23}$ The sum of the bond angles of the basal plane N(4)$\mathrm{Cu}(1)-\mathrm{O}(1)\left\{92.3^{\circ}\right\}, \mathrm{O}(1)-\mathrm{Cu}(1)-\mathrm{N}(1)\left\{92.2^{\circ}\right\}, \mathrm{N}(1)-$ $\mathrm{Cu}(1)-\mathrm{O}(2)\left\{91.9^{\circ}\right\}$ and $\mathrm{O}(2)-\mathrm{Cu}(1)-\mathrm{N}(4)\left\{82.5^{\circ}\right\}$ is $358.9^{\circ}$, which further confirms the slight deviation of $\mathrm{Cu}(1)$ from the basal plane. The N-methyl carbons $\mathrm{C}(23)$ and $\mathrm{C}(24)$ as well as the methylene carbon $\mathrm{C}(19)$ exhibits disorder.

The coordination environment around $\mathrm{Cu}(2)$ is $\mathrm{NO}_{3}$, in which the $\mathrm{Cu}(2)$ atom is coordinated to the Schiff base ligand via the imine nitrogen $\mathrm{N}(3)$, phenolate oxygen $\mathrm{O}(4)$ and the oxygen atom $\mathrm{O}(5)$ of the carboxylate group. The fourth bond is coordinated with the oxygen atom $\mathrm{O}(3)$ of the bridging carboxylate group from another Schiff base ligand. The sum of the bond angles $\mathrm{O}(3)-\mathrm{Cu}(2)-\mathrm{O}(5) \quad\left\{92.9^{\circ}\right\}, \mathrm{O}(5)-\mathrm{Cu}(2)-\mathrm{N}(3)\left\{84.7^{\circ}\right\}$, $\mathrm{N}(3)-\mathrm{Cu}(2)-\mathrm{O}(4)\left\{93.3^{\circ}\right\}$ and $\mathrm{O}(4)-\mathrm{Cu}(2)-\mathrm{O}(3)\left\{88.6^{\circ}\right\}$ around $\mathrm{Cu}(2)$ is $359.5^{\circ}$, which confirms the presence of $\mathrm{Cu}(2)$ ion in the basal plane.
While comparing the bond distances between the metal centres with the similar group of atoms of Schiff base ligand, like phenolate oxygen $\mathrm{Cu}(1)-\mathrm{O}(1)$ is 1.928 and $\mathrm{Cu}(2)-\mathrm{O}(4)$ is $1.903 \AA$, imine nitrogen atom $\mathrm{Cu}(1)$ $\mathrm{N}(4)$ is 1.937 and $\mathrm{Cu}(2)-\mathrm{N}(3)$ is $1.922 \AA$ and oxygen atom of the carboxylate group $\mathrm{Cu}(1)-\mathrm{O}(2)$ is 1.999 and $\mathrm{Cu}(2)-\mathrm{O}(5)$ is $1.923 \AA$, it is interesting to note that bond distances are shorter around $\mathrm{Cu}(2)$ when compared to that of $\mathrm{Cu}(1)$.

Similarly, while comparing the bond angles between the similar groups $\mathrm{O}(1)-\mathrm{Cu}(1)-\mathrm{N}(4)\left\{92.3^{\circ}\right\}$ and $\mathrm{O}(4)-$ $\mathrm{Cu}(2)-\mathrm{N}(3) \quad\left\{93.3^{\circ}\right\}, \mathrm{N}(4)-\mathrm{Cu}(1)-\mathrm{O}(2) \quad\left\{82.5^{\circ}\right\}$ and $\mathrm{N}(3)-\mathrm{Cu}(2)-\mathrm{O}(5)\left\{84.7^{\circ}\right\}$ it is to be noted that the bond angles around $\mathrm{Cu}(2)$ is greater than that of $\mathrm{Cu}(1)$, which may be due to the coordination environment around the central metal ion. The bond length of imine group C(1)$\mathrm{N}(4)$, attached with the five coordinated $\mathrm{Cu}$ (II) ion is $1.285 \AA$ and this is found to be slightly greater than the other imine group $\mathrm{C}(16)-\mathrm{N}(3)$, with the bond length $1.280 \AA$, attached with the four coordinated $\mathrm{Cu}$ (II) ion. The bridging of two copper(II) ions via carboxylate group of Schiff base ligand leads to a dinuclear moiety with syn-anti conformation. The separation between $\mathrm{Cu}(1) \ldots \mathrm{Cu}(2)$ is $5.06 \AA$.

The sum of the bond angles and the $\tau$ value around penta coordinated $\mathrm{Cu}$ (II) ions in both the complexes were found to be nearly same. As per the literature, ${ }^{28}$ the coordination mode of NN-donor chelating diamine displays axial-equatorial mode of bonding with the $\mathrm{Cu}$ (II) atom with square pyramidal geometry.

\subsection{FTIR spectroscopy}

In the FTIR spectra, the band observed at 1637 and $1641 \mathrm{~cm}^{-1}$ of the complexes $\mathbf{1}$ and $\mathbf{2}$ (figures S1 and S2, Supplementary Information), respectively, correspond to the coordinated imine group. The phenolic $v(\mathrm{C}-\mathrm{O})$ band for the complexes $\mathbf{1}$ and $\mathbf{2}$ appeared at 1193 and 
$1163 \mathrm{~cm}^{-1}$, respectively. The carboxylate group can coordinate in different ways via monodentate or bidentate to one metal ion or it can act as a bridging ligand between two metal ions. The coordination mode of the carboxylate group can be determined by FTIR spectroscopy. For bidentate chelating or bridging mode the separation between asymmetric and symmetric stretching $\left(\Delta v=v_{\mathrm{as}}-v_{\mathrm{s}}\right)$ frequencies of the carboxylate group is significantly less compared to that of the free carboxylate anion value, while the separation is more, compared to the free anionic value in case of unidentate mode. ${ }^{29}$

In the present case, for complex $1\left(v_{\mathrm{as}}=1533 \mathrm{~cm}^{-1}\right.$; $v_{\mathrm{s}}=1340 \mathrm{~cm}^{-1}$ ), the $\Delta v$ value is $193 \mathrm{~cm}^{-1}$ which is higher than that of free carboxylate anion $\left(145 \mathrm{~cm}^{-1}\right)$. This indicates a monodentate coordination of the carboxylate group of Schiff base ligand with copper(II) ion of complex 1 . In contrast, for complex $2, \Delta v$ value is $142 \mathrm{~cm}^{-1}\left(v_{\mathrm{as}}=1517 \mathrm{~cm}^{-1} ; v_{\mathrm{s}}=1375 \mathrm{~cm}^{-1}\right)$. This is in accordance with the single crystal XRD, and hence substantiate the bridging coordination mode of the carboxylate group ${ }^{30}$ between two copper(II) ions of complex 2. Further, the band observed for the complexes 1 and 2 at 545 and $574 \mathrm{~cm}^{-1}$, respectively, could be ascribed to $v(\mathrm{Cu}-\mathrm{N})$ coordination. While the band observed at 487 and $497 \mathrm{~cm}^{-1}$, for the complexes 1 and 2 respectively, are associated to $v(\mathrm{Cu}-\mathrm{O})$ bonding. ${ }^{31}$

\subsection{Electron Spin Resonance spectra}

To analyse the metal environment like geometry and the degree of covalency of metal-ligand bonds, ESR spectra of the complexes $\mathbf{1}$ and $\mathbf{2}$ (figures S3 and S4, in Supplementary Information) were recorded in polycrystalline state under liquid nitrogen temperature. For complex 1 $\left(\mathrm{g}_{\|}=2.05 ; \mathrm{g}_{\perp}=2.02\right)$, the $\mathrm{g}$ values indicate the axial symmetry and the relation $\mathrm{g}_{\|}>\mathrm{g}_{\perp}>2.0023$ holds for the components of the g-tensor. The square pyramidal configuration with $\mathrm{C}_{4 \mathrm{v}}$ symmetry point group is consistent with the parameters of the ESR spectra obtained, which satisfy the above mentioned relation. ${ }^{32}$ The geometric parameter $G,\left[\left(g_{\|}-2.0023\right) /\left(g_{\perp}-2.0023\right)\right]$, is a measure of the exchange interaction between copper centres in the polycrystalline compound. It is perceived that, the exchange interactions in the solid complex is negligible if $G>4$, while considerable exchange interaction occurs if $G<4$. For complex 1 , the $G$ value is found to be 1.9 , which is consistent with a $\mathrm{dx}^{2}-\mathrm{y}^{2}$ ground state and hence prove the presence of considerable exchange interaction in the solid state. ${ }^{33}$ The ESR spectrum of the complex 2 displayed an isotropic spectrum with the $\mathrm{g}_{\text {iso }}$ value of 2.02 , indicating an axial symmetry with all the principal axes aligned parallel. Such a spectrum is expected in complexes with elongated tetragonal-octahedral, square planar, or square based pyramidal stereo chemistry. ${ }^{34}$

\subsection{UV-Visible and CD spectra}

The electronic property and the structure of complexes $\mathbf{1}$ and $\mathbf{2}$ in solution state were compared by UV-Visible and CD spectroscopy (figure 3) recorded in ethanol. Both these spectroscopic techniques have been used to characterize the inorganic complexes in solution state. $^{35,36}$

In the electronic absorption spectrum (figures S5 and S6, in Supplementary Information), the complexes $\mathbf{1}$ and 2 exhibited an intense band at $225 \mathrm{~nm}$ and $240 \mathrm{~nm}$, respectively, accompanied by a shoulder band around $270 \mathrm{~nm}$ and $280 \mathrm{~nm}$, respectively. These bands are associated with $\pi \rightarrow \pi^{*}$ of benzene ring/intra ligand charge transfer (ILCT) transitions. Complexes $\mathbf{1}$ and $\mathbf{2}$ displayed an absorption band at $375 \mathrm{~nm}$ and $390 \mathrm{~nm}$, respectively, which are attributed to $n \rightarrow \pi *$ transition originating from electrons present on the nitrogen atom of the azomethine moiety. The difference in the absorption wavelength maxima between complexes $\mathbf{1}$ and $\mathbf{2}$ indicates that the electronic properties of these complexes are dissimilar. In UV region of the CD spectrum, complex 1 exhibited positive bands at $223 \mathrm{~nm}$ and 256 $\mathrm{nm}$ and negative bands at 208, 240 and $272 \mathrm{~nm}$. Similar to complex 1, positive bands at 228 and $253 \mathrm{~nm}$ and negative bands at 211 and $278 \mathrm{~nm}$ were observed for complex 2, except a negative band at $240 \mathrm{~nm} .{ }^{37}$ Further, the relative intensities of these bands are different between complex $\mathbf{1}$ and $\mathbf{2}$. The difference in the CD spectrum could be attributed to the difference in the structure of complexes $\mathbf{1}$ and $\mathbf{2}$.

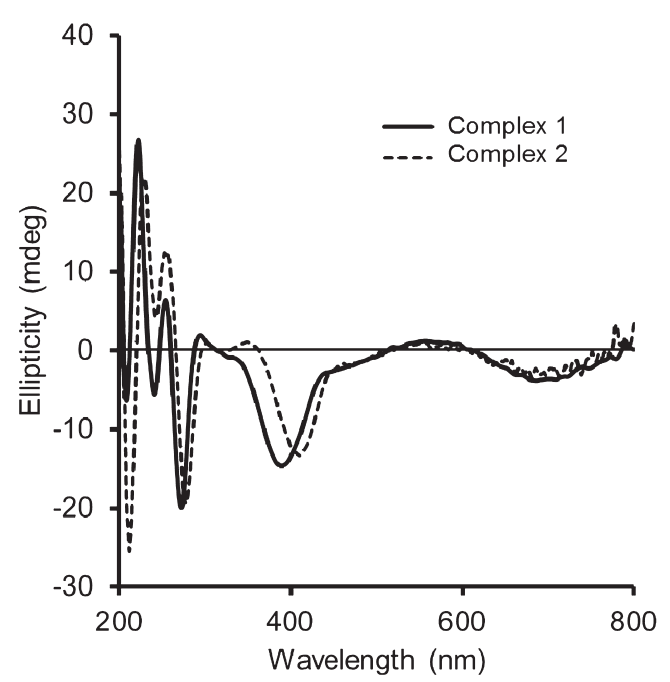

Figure 3. CD spectra of copper(II) complexes $\mathbf{1}$ and $\mathbf{2}$. 
According to the literature, the Schiff base complexes derived from salicylaldehye, the CD bands of imine groups appeared to be negative band and flanked by a shoulder band. ${ }^{38}$ Similarly, the CD spectra of the complexes 1 and 2 displayed bands at $388 \mathrm{~nm}$ and $412 \mathrm{~nm}$, respectively, with the negative Cotton effect, associated with $\mathrm{n} \rightarrow \pi^{*}$ transition of the azomethine group. This is accompanied a band at $318 \mathrm{~nm}$ and $325 \mathrm{~nm}$ for the complexes $\mathbf{1}$ and $\mathbf{2}$, respectively, as a shoulder band with negative Cotton effect. Again, the shift in the position of $\mathrm{CD}$ bands of both the complexes suggests the different geometries possessed by the complexes $\mathbf{1}$ and $\mathbf{2}$, in accordance with the single crystal XRD. However, it should be noted that the shift could also be caused by a wavelength maximum shift, as observed in the electronic spectrum.

In UV-Visible absorption spectrum, the d-d transitions were not observed owing to lower concentration of the $\mathrm{Cu}$ (II) complexes while, the same can be observed at higher concentrations. In contrast, CD spectra provide valuable information regarding $\mathrm{d}-\mathrm{d}$ transitions even at low concentrations of the metal complexes. In the visible region, both the complexes exhibited CD couplet, a negative band around $695 \mathrm{~nm}$ followed by a weak positive band around $570 \mathrm{~nm}$, which is attributed to the d-d transition. Such a type of CD spectrum is due to the asymmetric coordination environment around $\mathrm{Cu}$ (II) ion and the same has been previously observed for the metal complexes. ${ }^{39}$ The CD spectra thus suggest the asymmetric environment around $\mathrm{Cu}$ (II) ion in both the complexes.

\subsection{In vitro antidiabetic activity}

The results of glucose inhibitory assay are given in tables S3 and S4, in Supplementary information. The percentage inhibition of $\alpha$-amylase and $\alpha$-glucosidase exhibited by the complexes are depicted in table S5, in Supplementary information. $\mathrm{IC}_{50}$ values of complexes $\mathbf{1}$ and $\mathbf{2}$ are compared with standard drug acarbose and listed in table 1 .

Table 1. $\mathrm{IC}_{50}$ values of standard drug acarbose and the complexes.

\begin{tabular}{lcc}
\hline \multirow{2}{*}{ Sample } & \multicolumn{2}{c}{$\mathbf{I C}_{50}(\mu \mathrm{g} / \mathbf{m L})$} \\
\cline { 2 - 3 } & $\alpha$-amylase & $\alpha$-glucosidase \\
\hline Acarbose & $48.33 \pm 0.73$ & $42.19 \pm 0.09^{*}$ \\
Complex 1 & $941.20 \pm 0.09$ & $919.02 \pm 0.22$ \\
Complex 2 & $389.01 \pm 0.40$ & $350.02 \pm 0.24^{*}$ \\
\hline
\end{tabular}

Values are mean SEM for group of three observations, $p^{*}<0.05$.
Many researchers have focused on in vivo antidiabetic activities of copper complexes. ${ }^{19,40}$ Walter et al. ${ }^{41}$ hypothesized that copper metabolism encounters the diabetic pathological conditions. Copper can increase the tolerance of pancreatic $\beta$-cells against oxidative stress, which is one of the causative agents of diabetes. ${ }^{42}$ Intramuscular injection of copper(II) acetate imidazole complex to streptozotocin (STZ) induced rats are shown to increase in glucose tolerance and consequently decrease in blood glucose level. Abdul-Ghani et al., ${ }^{43}$ proved the antidiabetic effect of bis(acetato)tetrakis(imidazole) copper(II) in STZ induced diabetic rats. Yasumatsu et al. ${ }^{44}$ stated that single intraperitonial injection of copper(II) picolinate to diabetic mice shown higher hypoglycemic effect. Moreover, Barthel et al., ${ }^{45}$ proved that, the copper chelating agent tetrathiomolybdate decreased serum copper ions and free radicals which ameliorates glucose and lipid metabolism in diabetic $\mathrm{db} / \mathrm{db}$ mice model. The mechanism of action by copper has been suggested, that copper treats hyperglycemia by activating the phosphoinositide 3'kinase (PI3-K/Akt) pathway leading to GLUT 4 translocation $^{46}$ in some studies. Hence, the above studies indicate that $\mathrm{Cu}$ (II) complexes exhibit good antidiabetic activity.

In the current study, the inhibitory effect of copper(II) complexes $\mathbf{1}$ and $\mathbf{2}$ on carbohydrate hydrolysing enzymes $\alpha$-amylase and $\alpha$-glucosidase were investigated. These enzyme inhibitors antagonize the activity of these enzymes and delaying the digestion of carbohydrate which prevents the sudden rise in blood glucose level, especially after meal. ${ }^{47}$ Therefore, inhibition of these two enzymes is an attractive approach for the management of diabetes. In the present study, complex 2 inhibits $\alpha$-amylase $50.18 \pm 0.39 \%$ and acarbose inhibits $84.80 \pm 0.03 \%$. Complex 2 inhibits glucosidase $54.2 \pm 0.05 \%$ and complex 1 inhibits $20.52 \pm 0.40 \%$; these are compared with standard drug acarbose which inhibits $85.80 \pm 0.03 \%$. Hence, complex 2 is considered as moderate inhibitor when compared with complex $\mathbf{1}$. Complex 1 was least potent inhibitor for those enzymes. Relative movement of the complex $\mathbf{1}$ was $82.35 \pm 0.91 \%$ and complex 2 was $49.97 \pm 0.91 \%$. Complex 2 effectively retards the movement of glucose through the biomembrane after three hours. This suggested that the complex $\mathbf{2}$ can delay absorption compared to complex 1. The $\mathrm{IC}_{50}$ values of the copper(II) complexes $\mathbf{1}$ and $\mathbf{2}$ were much higher when compared with standard drug acarbose. The enhanced activity of complex $\mathbf{2}$ may be due to the electronegative chloro substituents present in the Schiff base ligand. Hence, some substituent changes in these complexes may help to exhibit potential inhibition on these enzymes and less diffusion through 
intestinal membrane. However, further in vivo studies are essential to prove their antidiabetic activity and the mechanism.

\section{Conclusions}

In summary, synthesis and characterization of two new copper(II) complexes derived from tridentate ONO donor Schiff bases N-(salicylidene)-L-valine and N-(3,5dichlorosalicylidene)-L-valine with tmen $\left(\mathrm{N}, \mathrm{N}, \mathrm{N}^{\prime}, \mathrm{N}^{\prime}-\right.$ tetramethylethylene-1,2-diamine) are described in this article. Complex $\mathbf{1}$ adopts a distorted square pyramidal geometry while complex $\mathbf{2}$ adopts a syn-anti mode of carboxylate bridged dinuclear structure, as revealed by single crystal XRD. The $\mathrm{IC}_{50}$ values of in vitro antidiabetic studies of both the complexes were much higher when compared with standard drug such as acarbose. Since both the complexes showed significant inhibiting activities, the current results provide a lead for the in vivo studies to establish the possibility of these complexes as antidiabetic agent.

\section{Supplementary Information (SI)}

CCDC 933779 (for complex 1) and 919273 (for complex 2) contain the supplementary crystallographic data for this paper. These data can be obtained free of charge at www.ccdc.cam.ac.uk/conts/retrieving.html. Crystal data and structure refinement for the copper(II) complexes 1 and $\mathbf{2}$ (table S1), Selected bond lengths $(\AA)$ and angles (deg) for complexes $\mathbf{1}$ and $\mathbf{2}$ (table S2), Diffusion of glucose through dialysis membrane to the external solution concentration of glucose (mg/dL) (table S3), Relative movement of glucose through dialysis membrane over 180 minutes (table S4), Inhibitory activity of complexes at varying concentrations on $\alpha$-amylase and $\alpha$-glucosidase compaed with standard drug acarbose table S5), FTIR (figures S1, S2), ESR (figures S3, S4) and electronic absorption spectra (figures S5, S6) of the complexes $\mathbf{1}$ and $\mathbf{2}$ are given in Supplementary Information, available at www.ias.ac.in/chemsci.

\section{Acknowledgements}

The authors express their gratitude to D.K.M. College for Women and Muthurangam Govt. Arts College, Vellore. S. S. L. thanks Dr. K. Gunasekaran, Department of Crystallography and Biophysics, University of Madras and Dr. Sivasankar Chinnappan, Department of Chemistry, Pondicherry University for single crystal XRD studies; VIT, Vellore, for antidiabetic studies; and Mr. J. Jayamani, CSIR-Senior Research Fellow, Bioorganic Chemistry Laboratory, CSIR-CLRI, Chennai, for his help in UV-Vis. and CD measurements.

\section{References}

1. Bailey C J and Day C 1989 Diabetes Care 12553

2. Sara K S F, Peter R F, Day C and Clifford J B 1991 Proc. Nutr. Soc. $\mathbf{5 0} 641$

3. Coulson L and Dandona P 1980 Diabetes 29665

4. Pandeya K B, Tripathi I P, Mishra M K, Dwivedi N, Pardhi P, Kamal P, Gupta Y, Dwivedi N and Mishra C 2013 Int. J. Org. Chem. 31

5. Inamo $M$, Kumagai $H$, Harada $U$, Itoh $S$, Iwarsuki $S$, Ishihara K and Takagi H 1703 Dalton Trans.

6. Harris E D 2003 Crit. Rev. Clin. Lab. Sci. 40547

7. Sorenson J R 1989 J. Prog. Med. Chem. 26437

8. Li X, Fang C, Zong Z, Cui L, Bi C and Fan Y 2015 Inorg. Chim. Acta $\mathbf{4 3 2} 198$

9. Perumal G, Jayaram R and Aziz K R 2014 J. Chem. Sci. 126783

10. Akhil R C, Pattubala A N A, Bidyut K S and Anitha M T 2002 J. Chem. Sci. 114391

11. Katwal R, Kaur H and Kapur B K 2013 Sci. Rev. Chem. Commun. 31

12. Zeinab M, Zhara A M B and Behrouz N 2013 Polyhedron $\mathbf{5 3} 7$

13. García-Raso Á, Juan F J, Adela Lápez-Zafra, Jose A, Castro, Araceli C, Ignasi M and Elies M 2003 Polyhedron 22403

14. Reddy P A N, Nethaji M and Chakravarty A R 2004 Eur. J. Inorg. Chem. 1440

15. Samya B, Akanksha D, Sesha M K, Basudev M, Sanjoy M, Kumar Arum, Anjali K and Chakravarty A R 2016 J. Chem. Sci. 128165

16. Rama I and Selvameena R 2015 J. Chem. Sci. 127671

17. Iran S, Yousef E S, Brahimipour Madiesh S, Maryam M, Mehdi A, Hadi A R and Giuseppe B 2015 J. Chem. Sci. 1272193

18. Jing H, Feng Y B, Hai Yan Z, Yong Heng X, Xiao Qing Z and Mao Fa G 2009 Chinese Sci. Bull. 543508

19. Vančo J, Marek J, Trávníčk Z, Račanská E, Muselík J and Švajlenová O 2008 J. Inorg. Biochem. 102595

20. Zhi-Qiang F, Xiao-Li Y, Yuan-Feng Y and Lin-Yun H 2014 Bull. Korean Chem. Soc. 351121

21. Saurabh D and Nidhi B 2013 Int. J. Curr. Pharm. Res. 56

22. (a) Sheldrick G M 1997 SHELXL-97, In Program for the Solution of Crystal Structures; (University of Göttingen:, Göttingen, Germany); (b) Sheldrick G M 1997 SHELXS-97 In Program for the Crystal Structure Refinement; (University of Göttingen: Göttingen, Germany)

23. Gayathri G A and Gayathri M 2014 Int. J. Pharm. Pharm. Sci. 6362

24. Geary W J 1971 Coord. Chem. Rev. 781

25. Naskar J P, Biswas C, Lu L and Zhu M 2011 J. Chem. Crystallogr. $\mathbf{4 1} 502$

26. Anthony W A and Nageswara R T 1984 J. Chem. Soc. Dalton Trans. 1349

27. Reddy P A N, Nethaji M and Chakravarty A R 2002 Inorg. Chim. Acta 337450

28. Dhar S, Nethaji M and Chakravarty A R 2005 Inorg. Chim. Acta 3582437

29. Xing Li M, Shao M, Dai H, Li An B, Cong Lu W, Zhu Y and Xia Du C 2005 Chin. Chem. Let. 161405

30. Choi Ki-Young 2008 J. Chem. Crystallogr. 3853 
31. Nakamoto K 1986 In Infrared and Raman Spectra of Inorganic and Coordination Compounds, 5th ed. (New York: John Wiley)

32. Valko M, Pelikan P, Biskupic S and Mazur M 1990 Chem. Papers 44805

33. Hathaway B J and Billing D E 1970 Coord. Chem. Rev. 51

34. Geetha K and Santhalakshmi S 2014 Res. J. Chem. Sci. 468

35. Edward S, Andrzej S, Magdalena B and Erik L 2002 Polyhedron 212711

36. Pradeep C P, Zacharias P S and Das S K 2005 J. Chem. Sci. 117133

37. Pessoa J C, Calhorda M J, Cavaco I, Costa P J, Correia I, Costa D, Vilas-Boas L F, Félix V, Gillard R D, Henriques R T and Wiggins R 2004 Dalton. Trans. 182855

38. Szlyk E, Surdykowski A, Barwiolek M and Larsen E 2002 Polyhedron 212711
39. Tao W, Xiao-Peng Z, Cheng-Hui L, Petr B, Yi-Zhi L and Xiao-Zeng Y 2012 Chirality 24451

40. Ling W, Jun W, Cai F Z, Yi J L, Lei Q C, Jun F and Hui Z 2010 Sci. China Chem. 531255

41. Walter J R M, Uriu-Hare J Y, Olin K L, Oster M H, Anawalt B D and Critchfield J W 1991 Diabetes Care 141050

42. Kubisch H M, Wang J, Luche R, Carlson E, Bray T M and Epstein C J 1994 Proc. Natl. Acad. Sci. 919956

43. Abdul-Ghani A S, Abu-Hijleh A L, Nahas N and Amin R 1996 Biol. Trac. Ele. Res. 54143

44. Yasumatsu N, Yoshikawa Y, Adachi Y and Sakurai H 2007 Bioorg. Med. Chem. 154917

45. Barthel A, Ostrakhovitch E A, Walter P L, Kampkötter A and Klotz L O 2007 Arch. Biochem. Biophy. 463175

46. Ostrakhovitch E A and Cherian M G 2004 Arch. Biochem. Biophy. 423351

47. Koyasu M, Ishili H, Watarai M, Takemoto K and Inden Y 2010 Clin. Theor. 321610 